Wright State University

CORE Scholar

Physics Faculty Publications

Physics

$5-1-1983$

\title{
Defect Nature of the 0.4-Ev Center in 0-Doped GaAs
}

David C. Look

Wright State University - Main Campus, david.look@wright.edu

S. Chaudhuri

J. R. Sizelove

Follow this and additional works at: https://corescholar.libraries.wright.edu/physics

Part of the Physics Commons

\section{Repository Citation}

Look, D. C., Chaudhuri, S., \& Sizelove, J. R. (1983). Defect Nature of the 0.4-Ev Center in O-Doped GaAs. Applied Physics Letters, 42 (9), 829-831.

https://corescholar.libraries.wright.edu/physics/29

This Article is brought to you for free and open access by the Physics at CORE Scholar. It has been accepted for inclusion in Physics Faculty Publications by an authorized administrator of CORE Scholar. For more information, please contact library-corescholar@wright.edu. 


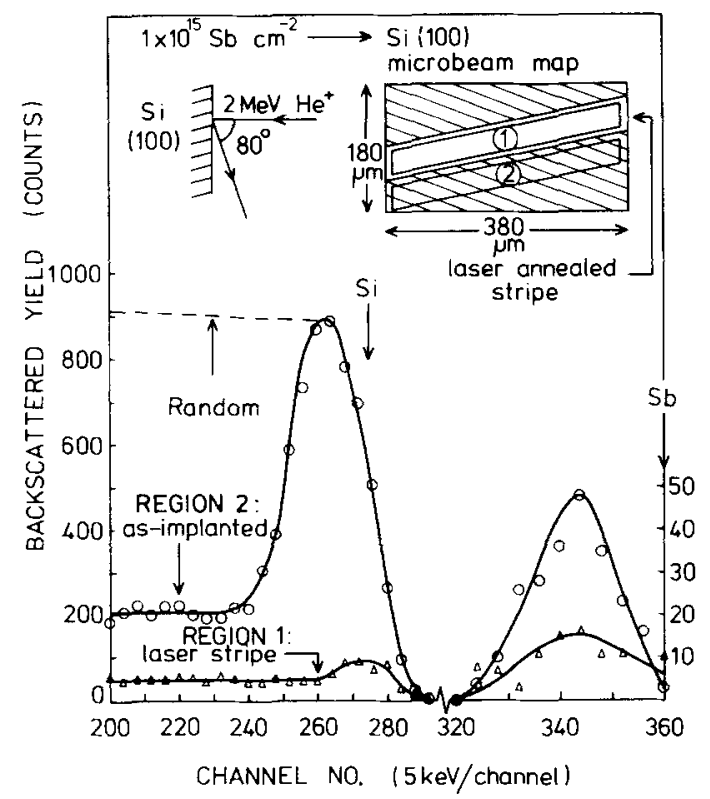

FIG. 3. Channeled microbeam spectra taken from selected areas of the map shown in Fig. 2(a). The spectra were obtained from areas of $\sim 30 \times 400 \mu \mathrm{m}^{2}$ both within and outside the laser stripe, as shown by the inset in the upper right.

al $\mathrm{Sb}$ ions would be displaced from lattice sites during the analysis, as has been previously observed by others. ${ }^{12}$ The relatively poor counting statistics for $\mathrm{Sb}$ has not allowed such a process to be investigated in the present experiments. However, the effect may limit quantitative microbeam analysis of atom location for sytems where the probe ions can modify the atom positions of certain foreign species in a host lattice.

In conclusion, we have demonstrated the capabilities of a channeled $\mathrm{He}^{+}$microbeam for measuring lateral variations in both disorder-depth distributions and atom location. It is expected that the technique may have important applications to semiconductor device technology as a means of imaging subsurface structural features in small-scale devices. Such applications will be reported elsewhere.

The Australian Research Grants Scheme is acknowledged for financial support.

\footnotetext{
${ }^{1}$ See for example, Ion Beam Analysis, edited by H. H. Andersen, J. Bøttiger, and H. Knudsen (North-Holland, Amsterdam, 1980).

${ }^{2}$ J. W. Mayer and E. Rimini, eds. Ion Beam Handbook for Material Analysis (Academic, New York, 1977).

${ }^{3}$ W. K. Chu, J. W. Mayer, and M. A. Nicolet, Backscattering Spectrometry (Academic, New York, 1978).

${ }^{4}$ J. A. Cookson, Nucl. Instr. Meth. 165, 477 (1979).

${ }^{5}$ S. A. Ingarfield, C. D. McKenzie, K. T. Short, and J. S. Williams, Nucl. Instr. Meth. 191, 521 (1981).

${ }^{6}$ G. J. F. Legge, C. D. McKenzie, and A. P. Mazzolini, J. Microse. 117, 185 (1979).

${ }^{7}$ J. S. Williams, Nucl. Instr. Meth. 149, 207 (1978).

${ }^{8}$ J. S. Williams, W. L. Brown, H. J. Leamy, J. M. Poate, J. W. Rodgers, D. Rousseau, G. A. Rozgonyi, J. A. Shelnutt, and T. T. Sheng. Appl. Phys. Lett. 33, 542 (1978).

${ }^{9}$ A. Lietoila, J. F. Gibbons, T. J. Magee, J. Peng, and J. D. Hong, Appl. Phys. Lett. 35, 532 (1979).

${ }^{10}$ F. A. Trumbore, Bell Syst. Tech. J. 39, 205 (1960).

"J. Narayan, G. L. Olson, and O. W. Holland, in Laser-Solid Interactions and Transient Thermal Processing of Materials, edited by J. Narayan, W L. Brown, and R. A. Lemons (North-Holland, New York, in press).

${ }^{12}$ L. W. Wiggers and F. W. Saris, Rad. Eff. 45, 162 (1979).
}

\title{
Defect nature of the 0.4-eV center in O-doped GaAs
}

\author{
D.C. Look and S. Chaudhuri \\ University Research Center, Wright State University, Dayton, Ohio 45435 \\ J. R. Sizelove \\ Air Force Avionics Laboratory, Wright-Patterson AFB, Ohio 45433
}

(Received 21 January 1983; accepted for publication 24 February 1983)

We have studied the $E_{c}-0.4 \mathrm{eV}$ center in O-doped GaAs by a combination of temperaturedependent Hall-effect measurements, spark-source mass spectroscopy, and secondary-ion mass spectroscopy. The conclusion is that neither $\mathrm{O}$ nor any other impurity can account for the 0.4-eV center; therefore, it is a pure defect.

PACS numbers: 71.55.Fr, 72.20.My, 72.80.Ey

It is well known that GaAs can be rendered semi-insulating (SI) by doping with $\mathrm{Cr}$ or $\mathrm{O} .{ }^{1}$ The latter dopant seems to induce three prominent levels at $E_{c}-0.15,0.43$, and 0.75 $\mathrm{eV}$, respectively. ${ }^{2}$ The $0.75-\mathrm{eV}$ level, also known as EL 2 from transient capacitance studies, ${ }^{3}$ is responsible for the SI nature of $\mathrm{O}$-doped $\mathrm{GaAs}$, and thus has been studied extensive1y. It is known ${ }^{4}$ that EL2 is not directly connected with $O$, and may, in fact, be associated with the antisite defect $\mathrm{As}_{\mathrm{Ga}} \cdot{ }^{5}$ The $0.15-\mathrm{eV}$ center, on the other hand, has definitely been shown to be a pure defect, not associated with any impurity. ${ }^{6}$
In contrast, the $0.4-\mathrm{eV}$ center has not been investigated to nearly the extent of EL2, although several different experimental techniques seem to give consistent values for the energy: 0.43 (Hall effect, this study); 0.46 [photoconductivity (PC) threshold, $\left.100^{\circ} \mathrm{K}\right]^{7} ; 0.42\left(\mathrm{PC} \text { threshold, } 77^{\circ} \mathrm{K}\right)^{8} ; 0.46 \mathrm{eV}$ (photocapacitance threshold, $90^{\circ} \mathrm{K}$ ). ${ }^{9}$ Perhaps the most extensive investigation of this center has been carried out by Arikan, Hatch, and Ridley (AHR), who have deduced ${ }^{10}$ a PC threshold at $\left(0.420-1.2 \times 10^{-4} \mathrm{~T}\right) \mathrm{eV}$.

In this letter we report Hall-effect data for $\mathrm{a}_{2} \mathrm{Ga}_{3}$ - 


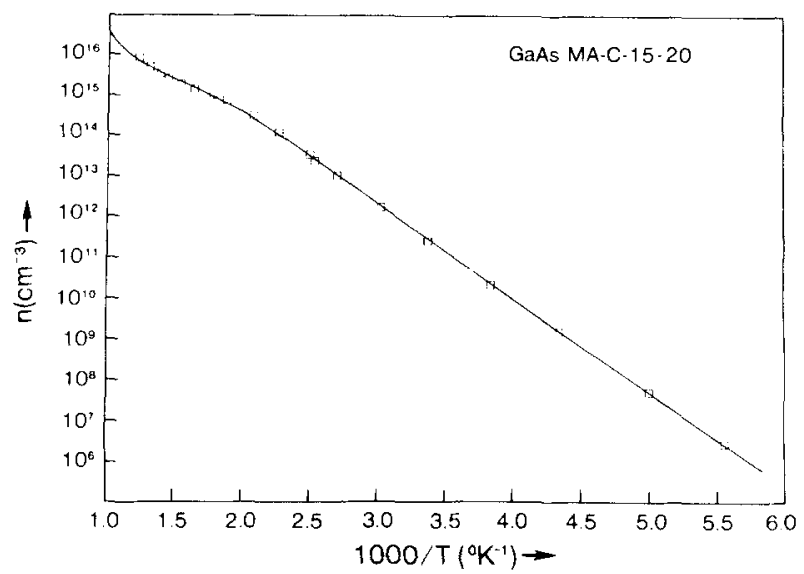

FIG. 1. Free-electron concentration vs inverse temperature for GaAs sample MA-C-15-20. The solid line is a theoretical fit to Eq. (1), text, using the parameters given in Table $\mathbf{I}$.

doped, liquid-encapsulated Czochralski crystal, MA-C-1520. The dominant donor concentration is determined by fitting the carrier concentration $(n)$ vs $T$ data over a nine-decade concentration range. Finally, we compare with analytical measurements (spark-source mass spectroscopy and secondary-ion mass spectroscopy) to show that the $0.4-$ $\mathrm{eV}$ center is a pure defect, not associated with any impurity.

Hall-effect measurements were carried out from 180$810 \mathrm{~K}$ in an automated system described earlier. ${ }^{11}$ The freeelectron concentration was determined from the relationship $n=|r / e R|$, where $e$ is the electronic charge and $R$ the Hall coefficient. The Hall factor $r$ was deduced from an iterative solution of the Boltzmann equation, following Rode ${ }^{12}$ and Nag. ${ }^{13}$ All important scattering mechanisms were included. However, the chief parameter in the ionized-impurity scattering rate, namely, the ionized impurity concentration $\left(N_{I}\right)$, was allowed to vary until a best fit to the temperature-dependent mobility data was obtained. Since $N_{I}=2 N_{\mathrm{AS}}+n\left(N_{\mathrm{As}}\right.$ is defined below $)$, the fitting process had to be carried out self-consistently. The values of $r$ so obtained ranged from 1.03 to 1.15 over the indicated temperature range.

The $n$ vs $T$ data, shown in Fig. 1, were then fitted to the following simple change-balance equation ${ }^{14}$ :

$$
\frac{n_{i}^{2}}{n}+N_{\mathrm{DS}}+\frac{N_{D}}{1+n / \phi_{D}}=n+N_{\mathrm{AS}},
$$

where $N_{\mathrm{DS}}\left(N_{\mathrm{AS}}\right)$ is the concentration of all donors (acceptors) lying more than a few kT above (below) the Fermi level, $n_{i}$ is the intrinsic carrier concentration, and

$$
\phi_{D}=\frac{g_{0}}{g_{1}} e^{\alpha / k} N_{c}^{\prime} T^{3 / 2} e^{-E_{D O} / k T} .
$$

Here, $g_{0}\left(g_{1}\right)$ is the degeneracy of the unoccupied (occupied) donor level of interest, $N_{C}^{\prime}=2\left(2 \pi m_{n}^{*} k\right)^{3 / 2} / h^{3}$ and the temperature-dependent energy of this donor is defined by $E_{D}=E_{D O}-\alpha T$. Note that it is essential to maintain the $n_{i}$ term in Eq. (1) at the higher temperatures. function

The fit to Eq. (1) was carried out by minimizing the

$$
\chi^{2}=\frac{1}{N} \sum_{i=1}^{N}\left[\log \left(\frac{n_{i}^{\text {theo }}}{n_{i}^{\text {expt }}}\right)\right]^{2},
$$

where $N$ is the number of data points. The best fit is shown as the solid line in Fig. 1. However, it is also desirable to establish meaningful error ranges for the fitting parameters, namely, $E_{D O}, N_{D}, N_{\text {As }}-N_{\text {DS }}$, and $\left(g_{1} / g_{0}\right) \exp (-\alpha / k)$. This was done by varying each parameter around its best value while simultaneously allowing the other three parameters to float, thus obtaining a $\chi_{\min }^{2}$ curve as a function of the given parameter. The error range was defined as the higher and lower limits of the parameter which produced a $50 \%$ increase in $\chi_{\text {min }}^{2}$ relative to its best (lowest) value. Note that this arbitrary criterion is somewhat conservative, but still allows us to draw some important conclusions regarding the nature of the 0.4-eV center.

The results of this fitting procedure are given in Table I. Only $E_{D O}$ could be determined with high precision, because the other three parameters are strongly influenced by data in the high-temperature region, where intrinsic excitation obscures the excitation due to the center of interest. (We have used Blakemore's temperature dependence for the intrinsic carrier concentration. ${ }^{15}$ ) Because of this problem we can state with certainty only that $1 \times 10^{16} \leqslant N_{D} \leqslant 8 \times 10^{16} \mathrm{~cm}^{-3}$, with the best value being $N_{D}=2 \times 10^{16} \mathrm{~cm}^{-3}$.

The electrical analysis can also be carried out by assuming that the 0.4-eV center is an acceptor, with Eq. (1) appropriately modified. However, $\chi^{2}$ for the best acceptor fit is double that of the best donor fit; thus, the electrical data indicate that this center is a donor.

Sample MA-C-15-20 was analyzed for trace impurity content by spark-source mass spectroscopy (SSMS), and secondary-ion mass spectroscopy (SIMS). ${ }^{16}$ Both techniques were improved by liquid-helium cryopumping in an attempt to reduce $\mathrm{C}$ and $\mathrm{O}$ backgrounds, which were $2 \times 10^{15}$ and $1 \times 10^{15} \mathrm{~cm}^{-3}$, respectively, for the SSMS instruments, and $3 \times 10^{15}$ and $3 \times 10^{16} \mathrm{~cm}^{-3}$, respectively, for the SIMS instrument. The SIMS spectrometer had been calibrated for $\mathrm{C}$, $\mathrm{Si}, \mathrm{S}, \mathrm{Se}, \mathrm{Te}, \mathrm{B}, \mathrm{Mg}, \mathrm{Cr}, \mathrm{Mn}$, and $\mathrm{Fe}$, and relative concentrations were also obtained for $\mathrm{Cu}, \mathrm{Ge}, \mathrm{Sn}, \mathrm{Au}, \mathrm{Be}, \mathrm{Al}$, and $\mathrm{Zn}$. The SSMS method, on the other hand, is known to be accurate within a factor 3 , without special calibration, for virtually all elements between $\mathrm{Li}$ and $\mathrm{U} .^{17}$

We first note that all impurity concentrations, as measured by SSMS, were below $2 \times 10^{15} \mathrm{~cm}^{-3}$, except for Se, Ge,

TABLE I. Parameter values deduced from a fit of the $T$-dependent Hall-effect data to Eq. (1). The error values quoted are defined in the text.

\begin{tabular}{llll}
\hline $\begin{array}{l}E_{D} \\
(\mathrm{eV})\end{array}$ & $\begin{array}{l}N_{D} \\
\left(\mathrm{~cm}^{-3}\right)\end{array}$ & $\begin{array}{l}\left(N_{\mathrm{As}}-N_{\mathrm{DS}}\right) \\
\left(\mathrm{cm}^{-3}\right)\end{array}$ & $\left(g_{\mathrm{g}} / g_{0}\right) \exp (-\alpha / k)$ \\
\hline $0.429 \pm 0.008$ & $8_{-1}^{+5} \times 10^{16}$ & $1.8_{-1.3}^{+2.9}$ \\
\hline
\end{tabular}


and $\mathrm{Zn}$, which have a limiting background sensitivity of $9 \times 10^{15} \mathrm{~cm}^{-3}$. (The SSMS sensitivities for $\mathrm{Se}, \mathrm{Ge}$, and $\mathrm{Zn}$ are poorer because of their mass similarities to $\mathrm{Ga}$ and As, which "fog" the photoplates in this mass region.) The SIMS results, however, showed Se at only $3 \times 10^{11} \mathrm{~cm}^{-3}$, and even though the $\mathrm{Ge}$ and $\mathrm{Zn}$ concentrations were uncalibrated, we can use known sensitivity factors ${ }^{18}$ to estimate their concentrations at less than $1 \times 10^{13}$ and $4 \times 10^{15} \mathrm{~cm}^{-3}$, respectively. Both of these values are background limited (as shown by comparison with a pure sample), so that they should be considered as upper limits in our sample. Furthermore, $\mathrm{Zn}$ and $\mathrm{Ge}$ preferentially form shallow centers and have never, to our knowledge, been detected as deep, electrically active centers. Thus, the upper limit on every possible impurity element is at least a factor 3 below the lower limit of the donor concentration.

Within the limits of our electrical and analytical studies of sample MA-C-15-20, we can state that the dominant electrical center is (1) a donor, (2) a pure defect, and (3) lies 0.429 $\mathrm{eV}$ from the conduction-band edge at $T=0$. In investigations of two different samples, both grown by the Bridgman method, we found activation energies of 0.426 and $0.429 \mathrm{eV}$, respectively. Thus, the energy of this center is quite well fixed, which seems to indicate that a single species of the defect is involved. Note that the $0.15-\mathrm{eV}$ center has also been proven to be a defect, ${ }^{6}$ and the $0.75-\mathrm{eV}$ center (EL2) is also thought to be ${ }^{5}$ Since they are all found primarily in O-doped samples, it is reasonable to suppose that there might exist some relationships between them. For example, if EL2 is related to $A s_{G a}$, it might be expected to show two donor ionization energies. In fact, our sample also showed a strong photoluminescence line in the oxygen-EL2 spectral region $(0.63-0.68 \mathrm{eV}),{ }^{19}$ an expected observation since EL2 is typically present at the $10^{16} \mathrm{~cm}^{-3}$ level in this type of sample. ${ }^{20}$ Such possible relationships bear further investigation.

It is interesting to consider our results in light of the studies mentioned earlier. Four of these investigations ${ }^{7-10}$ essentially involved measurements of theoptical (absorption) energy, while our study yielded a thermal energy. Since all results are within $0.04 \mathrm{eV}$ of each other, and since all the samples were similarly prepared (i.e., $O$ doped) it seems reasonable to suggest that the same center is involved in each of these measurements, and that the Franck-Condon (FC) shift is not larger than about $0.04 \mathrm{eV}$. However, Arikan et al. $(\mathrm{AHR})^{10}$ analyzed their PC data in terms of a much larger FC shift, about $0.11 \mathrm{eV}$, which would place the thermal energy of their center at about $0.30 \mathrm{eV}$. Such a thermal energy has never been directly measured in GaAs, to our knowledge. Furthermore, Malinauskas et al. (MPF) interpreted an $0.42-\mathrm{eV}$ PC threshold measurement, in a sample with an $0.18-\mathrm{eV}$ Hall-effect activation energy, as evidence of an even larger FC shift: $0.24 \mathrm{eV}$. If either of these interpretations is correct, then we have the highly coincidental situation of $\mathrm{O}$ doped $\mathrm{GaAs}$ possessing two rather dominant, but unrelated centers, one with a thermal energy at $0.43 \mathrm{eV}$, and the other with an optical energy at $0.42 \mathrm{eV}$. It is much simpler, of course, to suppose that these two centers are really the same, with the FC shift being quite small. If so, then the temperature dependence measured by AHR, i.e., $\alpha=1.4 \times 10^{-4}$ $\mathrm{eV} / \mathrm{K}$, can be used to separate $\left(g_{1} / g_{0}\right)$ from the measured value of $\left(g_{1} / g_{0}\right) \exp (-\alpha / k)$, in Table I. However, from the present data, the latter term is too poorly determined to make such a separation worthwhile. Samples with a higher concentration of the $0.4-\mathrm{eV}$ center would probably yield more precise parameters, because of a smaller masking effect due to intrinsic conduction at the higher temperatures.

We wish to thank T. A. Cooper for the electrical measurements, P. W. Yu for the photoluminescence measurements, D. C. Walters for the SSMS data, and C. A. Evans for the SIMS data. In addition, we are grateful to $R$. Linares, Microwave Associates, for provision of the O-doped GaAs crystal. This work was carried out at the Avionics Laboratory, Wright-Patterson AFB, and was partially supported by USAF contract F33615-81-C-1406.

'For a recent review of semi-insulating GaAs, see G. J. Rees, ed. SemiInsulating III-V Materials, Nottingham, 1980 (Shiva, Nantwich, 1980).

${ }^{2}$ A. L. Lin, E. Omelianovski, and R. H. Bube, J. Appl. Phys. 47, 1852 (1976), and references therein.

${ }^{3}$ G. M. Martin, A. Mitonneau, and A. Mircea, Electron. Lett. 13, 191 (1977).

${ }^{4}$ A. M. Huber, N. T. Linh, M. Valladon, J. L. Debrun, G. M. Martin, A. Mitonneau, and A. Mircea, J. Appl. Phys. 50, 4022 (1979).

${ }^{5}$ J. Lagowski, J. M. Parsey, M. Kaminska, K. Wada, and H. C. Gatos, in Semi-Insulating III-V Materials, Evian, 1982, edited by S. Makram-Ebeid and B. Tuck (Shiva, Nantwich, 1982), p. 154.

${ }^{6}$ D. C. Look, D. C. Walters, and J. R. Meyer, Solid State Commun. 42, 745 (1982).

${ }^{7}$ H. G. Grimmeiss and L. A. Ledebo, J. Appl. Phys. 46, 2155 (1975).

${ }^{8}$ R. A. Malinauskas, L. Ya. Pervova, and V. I. Fistul, Sov. Phys. Semicond. 13, $1330[1979]$.

${ }^{9}$ P. K. Vasudev and R. H. Bube, Solid State Electron. 21, 1095 (1978).

${ }^{10}$ M. C. Arikan, C. B. Hatch, and B. K. Ridley, J. Phys. C 13, 635 (1980).

'D. C. Look and J. W. Farmer, J. Phys. E 14, 472 (1981).

${ }^{12}$ D. L. Rode, Phys. Rev. B 2, 1012 (1970).

${ }^{13}$ B. R. Nag, Electron Transport in Compound Semiconductors (Springer, New York, 1980).

${ }^{14}$ D. C. Look, Phys. Rev. B 24, 5852 (1981).

${ }^{15}$ J. S. Blakemore, J. Appl. Phys. 53, 520 (1982).

'The SIMS data were obtained from C. A. Evans and Associates, San Mateo, California.

${ }^{17} \mathrm{~J}$. B. Clegg, Semi-Insulating III-V Materials, Evian, 1982, edited by S. Makram-Ebeid and B. Tuck (Shiva, Nantwich, 1982), p. 80.

${ }^{18}$ A. E. Morgan and J. B. Clegg, Spectrochim. Acta Pt. B 35, 281 (1980)

${ }^{19}$ P. W. Yu and D. C. Walters, Appl. Phys. Lett. 41, 863 (1982).

${ }^{20}$ G. M. Martin, J. P. Farges, G. Jacob, J. P. Hallais, and G. Poibland, J. Appl. Phys. 51, 2840 (1980) 